\title{
CAUSES OF DEATH IN HOSPITALIZED HIV PATIENTS IN THE EAR- LY ANTI-RETROVIRAL THERAPY ERA
}

\author{
M. LARTEY ${ }^{1,4}$, A. ASANTE-QUASHIE ${ }^{2}$, A. ESSEL ${ }^{3}$, E. KENU ${ }^{4}$, V. GANU ${ }^{4}$ and A. NEEQUAYE ${ }^{1,4}$ \\ ${ }^{1}$ Department of Medicine, University of Ghana Medical School, College of Health Sciences, Korle Bu, Accra, \\ Ghana ${ }^{2}$ International Organization for Migration, Accra, Ghana, ${ }^{3}$ Department of Community Health, Uni- \\ versity of Ghana Medical School, Korle Bu. ${ }^{4}$ Department of Medicine, Korle-Bu Teaching Hospital, Korle-Bu, \\ Accra, Ghana.
}

DOI: $h t t p: / / d x$. doi.org/10.4314/gmj.v49i1.2

Corresponding author: Professor Margaret Lartey

E-mail address: malart38@yahoo.com

Conflict of Interest: None declared

\section{SUMMARY}

Objective: To establish the cause(s) of death among persons with HIV and AIDS admitted to the Fevers Unit of the Korle-Bu Teaching Hospital (KBTH) in 2007 and to determine whether they were AIDS-relatedin the era of availability of HAART

Method: Retrospective chart review of all deaths that occurred in the year 2007 among inpatients with HIV infection. Cause of Death (COD) was established with post mortem diagnosis, where not available ICD-10 was reviewed independently by two physicians experienced in HIV medicine and a consensus reached as to the most likely COD.

Results: In the year under review, 215 (97\%) of the 221 adult deaths studied were caused by AIDS and HIV-associated illnesses. Of these, 123 (55.7\%) were due to an AIDS-defining illness as described in CDC Category 3 or WHO stage 4. Infections accounted for most of the deaths 158 $(71.5 \%)$, many of them opportunistic $82(51.8 \%)$. Tuberculosis was the commonest COD. Clinical diagnosis of TB was accurate in 54\% of deaths, but was not validated by autopsy in $36 \%$ of deaths. There were few deaths $(14.5 \%)$ in patients on HAART.

Conclusion: In a developing country like Ghana where HAART was still not fully accessible, AIDS-related events remained the major causes of death in persons living with HIV. Total scale-up of the ART programme with continuous availability of antiretrovirals is therefore imperative to reduce deaths from AIDS and HIV associated illnesses. There is need for interventions for early diagnosis as well as reduction in late presentation and also better diagnostic tools for tuberculosis.

Keywords Cause of death, HIV, AIDS, HAART, Ghana, Tuberculosis

\section{INTRODUCTION}

HIV/AIDS is among the leading cause of death worldwide, with a yearly toll of 3.1 million. Most deaths ( 2.4 million) occur in sub-Saharan Africa. ${ }^{1}$ However, there has been a reduction in AIDS-related deaths and a corresponding increase in non-AIDS-related deaths in the era of highly active antiretroviral therapy (HAART), especially in developed nations. ${ }^{2-6}$ This phenomenon has been attributed to the increased longevity and better quality of life afforded by HAART.

As more countries scale up antiretrovirals, the phenomenon is also being noted across the world in middle and lower income countries. ${ }^{3,7,8}$ AIDS defining illnesses like cryptococcal meningitis, herpes simplex encephalitis, cerebral toxoplasmosis and extrapulmonary tuberculosis are giving way to sepsis, cardiovascular diseases, injuries and non AIDS defining cancers.

In developing countries where the majority of HIVinfected people live, access to HAART has improved, however there still remains a substantial unmet need for antiretroviral therapy. In the treatment 2015 initiative, the UNAIDS recognizes that access to ante-retroviral therapy (ART) be scaled up so that 15 million persons without ART have access by 2015. Ninety percent of those without access who are eligible are found in 30 countries most of which are low and middle income countries. ${ }^{9}$

Initially the high cost and complexity of administration of ART in low income countries was considered a barrier but evaluation of one of the earliest programmes showed similar virological, immunological and adverse effect outcome as in developed countries. ${ }^{10}$

Ghana started its ART programme in 2003 and Korle Bu Teaching Hospital (KBTH) was one of the initial sites to offer ART on a large scale. 
The study sought to determine the spectrum of causes of death (COD) among HIV-infected inpatients four years after provision of ART at the KBTH.

\section{BACKGROUND}

The Fevers Unit of Korle-Bu Teaching Hospital serves as the national referral centre for HIVinfected patients. Since the first case of HIV was diagnosed in Ghana in 1986, the Unit has provided care and support to persons living with HIV/AIDS.

In December 2003, the Unit became the third public site to provide HAART in the scale-up of access to treatment by the National AIDS Control Programme (NACP) and its partners. At the time of the study there were about 7000 patients enrolled, and 3192 of these were receiving HAART. There were 716 admissions to the ward in the year under study.

We explore here in detail the causes of death among HIV-infected patients admitted at the Korle$\mathrm{Bu}$ Teaching Hospital in the year 2007, 4 years after the national HAART programme was launched at the Fevers Unit.

\section{METHODS}

\section{Study Design}

This was a retrospective study in which the medical and mortality records of all HIV-infected patients who died at the Fevers Unit during the study period (January 2007 to December 2007) were reviewed. Data from multiple sources were used and triangulated. The multiple sources included one or more of the following: death certificates, medical charts, and autopsy reports, where available. The multiple sources also included electronic data capture from the database as well as manual records from the patient folders which included more details of outpatient as well as all details of inpatient admission. Some of the inpatient records were doctors' notes, nurse's notes and results of laboratory tests. Causes of death (COD) were collated from the death certificates and matched with autopsy results.

Where autopsy results were not available, two physicians experienced in HIV medicine using the medical records of admission and concordance established did independent determination of the most likely cause of death. In cases of discordance, a third experienced physician reviewed the records and consensus was reached as to the most likely primary and secondary CODs, taking into account the morbidity at the time of death. Cause of death was coded according to the International Classification of Diseases, 10th Revision (ICD-10). Variables studied included age, gender, duration of admission at the time of death, HAART use, and morbidity. "Morbidity" represented the number of concurrent illnesses present at the time of death.

Primary causes of death were classified as "AIDS-related death" (ARD), "HIV-associated death" (HIA), or "Other". A death was considered "AIDS-related" when the primary COD was an AIDS-defining event as described in Category 3 of the CDC definition of $\operatorname{AIDS}^{11}$, or WHO stage 4 . "HIV-associated deaths" included those conditions that were HIV related but not CDC category 3 or WHO stage 4 . A cause of death not directly attributable to either of the foregoing was characterized as "Other", i.e. non-HIVassociated. This category included conditions such as hepatic disease or cardiovascular disease from hypertension.

Causes of death were also sub-categorized by organ systems and stratified into "Opportunistic infection", "Opportunistic malignancy", or "Other". Examples of conditions falling into this last category were malignancies such as hepatocellular carcinoma and metastatic choriocarcinoma.

\section{Data management}

Data was entered into an excel workbook and cleaned. Missing data were filled in where available and duplications removed. The data was then exported into STATA version 8.2 and variables coded for analysis.

\section{Statistical Analysis}

Statistical comparisons were made using the chi-squared test of hypothesis or Fisher's exact test, where appropriate. $P$ values were two-tailed, and values of $<0.05$ were considered statistically significant. All analyses were done using a standard statistical package, STATA, version 8.2 (Stata Corp., College Station, Texas).

\section{Ethics}

The study protocol was reviewed and approved by the Ethical and Protocol Review Committee of the University of Ghana Medical School.

\section{RESULTS}

\section{Demographic Characteristics}

Between January and December 2007, a total of 716 HIV and AIDS patients were admitted to the Fevers Unit of which 221 of these patients died on admission giving a crude mortality rate of $31.5 \%$. Autopsy records were available for $135(61 \%)$ of the deaths. The mean age was 39.7 (SD 9.01) and the age range was 18-80 years. Patients in the reproductive age group (15-49) made up $187(84.6 \%)$ whilst females made up 115 (52\%) of the population. 
The majority of patients $116(53 \%)$ spent between one and six days on admission before death. Only $32(14.5 \%)$ of the patients were on HAART at the time of death (Table 1).

\section{Causes of Death}

Out of the total deaths, $215(97.3 \%)$ were caused by conditions associated with HIV and AIDS and $6(2.7 \%)$ were caused by non-HIV related conditions. Of the HIV and AIDS related deaths, 123 (57.21\%) were due to an AIDS-defining illness as described in Category 3 of the CDC definition of AIDS and therefore were categorized as AIDSrelated deaths (ARD) (Table 2) whereas 92 deaths (42.79\%) were non AIDS related and classified as HIV-associated deaths (HIA).

Table 1 Comparison of patients dying from AIDS Related deaths (ADR) and HIV Associated deaths (HIA)

\begin{tabular}{|c|c|c|c|}
\hline $\begin{array}{l}\text { Factor(at time } \\
\text { of death) }\end{array}$ & $\begin{array}{ll}\text { AIDS } & \text { re- } \\
\text { lated } & \\
\text { deaths } & \text { No } \\
(\%) & \\
(\mathrm{N}=123) & \\
\end{array}$ & $\begin{array}{l}\text { HIV associ- } \\
\text { ated deaths } \\
\text { No(\%) } \\
(\mathrm{N}=92)\end{array}$ & p-value \\
\hline \multicolumn{4}{|l|}{ Age (yrs) } \\
\hline $15-49$ & $103(83.7)$ & $79(85.9)$ & 0.81 \\
\hline$>49$ & $20(16.3)$ & $13(14.1)$ & \\
\hline \multicolumn{4}{|l|}{ Sex } \\
\hline Males & $61(49.6)$ & $42(44.7)$ & 0.71 \\
\hline Females & $63(50.4)$ & $50(54.3)$ & \\
\hline \multicolumn{4}{|c|}{ Duration of Admission at time of death } \\
\hline$<24 \mathrm{hrs}$ & $2(2)$ & $6(6)$ & 0.85 \\
\hline $1-6$ days & $65(55.5)$ & $50(49.5)$ & \\
\hline 7 days or more & $50(42.5)$ & $45(44.5)$ & \\
\hline \multicolumn{4}{|l|}{ HAART use } \\
\hline Yes & $16(13.6)$ & $16(15.8)$ & 0.80 \\
\hline No & $101(86.4)$ & $85(84.2)$ & \\
\hline \multicolumn{4}{|l|}{ Morbidity } \\
\hline $\begin{array}{l}0 \quad \text { concurrent } \\
\text { illnesses }\end{array}$ & $48(41.1)$ & $27(26.7)$ & $<0.01 *$ \\
\hline $\begin{array}{l}1 \text { concurrent } \\
\text { illness }\end{array}$ & $45(38)$ & $42(41.6)$ & \\
\hline $\begin{array}{l}2 \quad \text { concurrent } \\
\text { illnesses }\end{array}$ & $23(20)$ & $20(19.8)$ & \\
\hline $\begin{array}{l}3 \text { or more con- } \\
\text { current illnesses }\end{array}$ & $1(0.9)$ & $12(11.9)$ & \\
\hline
\end{tabular}

Tuberculosis was the commonest cause of death accounting for $69(57.7 \%)$ of all deaths. This was followed closely by cerebral toxoplasmosis and Kaposi's sarcoma.

HIV associated deaths consisted mainly of infections (47.8\%), anaemia (27.2\%), malignancy $(4.3 \%)$ and a large miscellaneous group (20.7\%) consisting of venous thromboembolism, pulmonary oedema and others (see Table 3 ).
Infections were again the commonest cause of HIV associated deaths majority of which were lobar or bronchopneumonia. This was followed closely by anaemia.

\section{Accuracy of Pre-mortem Diagnosis}

Autopsy findings were fully in agreement with pre-mortem diagnoses in $24.44 \%$ (33) of cases, partial agreement in $51.85 \%$ (70) and not in agreement with $23.70 \%$ (32) of cases.

Table 2 AIDS Related Deaths

\begin{tabular}{|l|l|}
\hline Infections N=110 & $\mathbf{N}(\mathbf{\%})$ \\
\hline Disseminated TB & $45(36.5)$ \\
\hline TB meningitis & $7(6.2)$ \\
\hline Pulmonary TB & $17(15)$ \\
\hline Cerebral Toxoplasmosis & $26(23)$ \\
\hline Cryptococcal meningitis & $4(3.5)$ \\
\hline Bacterial meningitis & $3(2.6)$ \\
\hline Chronic diarrhea & $8(7)$ \\
\hline Malignancies N-13 & \\
\hline Kaposi's sarcoma & $10(8.6)$ \\
\hline Lymphoma & $3(2.6)$ \\
\hline
\end{tabular}

Table 3 HIV Associated Deaths

\begin{tabular}{|l|l|}
\hline HIV Associated deaths N-92 & N (\%) \\
\hline Infections & $44(47.8)$ \\
\hline Anaemia & $25(27.2)$ \\
\hline Miscellanous & $19(20.7)$ \\
\hline Malignancy & $4(4.3)$ \\
\hline
\end{tabular}

\section{Accuracy of TB Diagnoses}

The ante mortem diagnosis of 69 cases of TB was validated using post mortem diagnosis. Clinical diagnosis of TB was accurate in $37(54 \%)$ of TB deaths, but was not validated by autopsy in $25(36 \%)$ of cases, revealing a considerably high index of suspicion for the disease. The diagnosis was missed in $7(10 \%)$ of patients.

\section{DISCUSSION}

The causes of death for HIV-infected patients admitted to the Fevers Unit in 2007 were examined. The data showed that AIDS-related events continued to be the major causes of death, in contrast to recent studies conducted in industrialized countries which had noted a shift in the causes of death toward non-HIV-related causes since the introduction of HAART. ${ }^{2,12-14}$

Sackoff ${ }^{12}$ noted in his study that from 1999-2004, the percentage of deaths from non-HIV causes had increased by $32 \%$, whereas Palella ${ }^{14}$ also found that the proportion of deaths attributable to non AIDS diseases had increased and were predominantly hepatic, cardiovascular, pulmonary and non AIDS defining cancers. In the study by De Ollala et $\mathrm{al}^{4}$, cause of death from non HIV related causes was $28 \%$ with cancers contributing $20 \%$ and liver diseases $18.8 \%$. 
In this cohort however, non-AIDS-related causes of death such as non-opportunistic malignancies, cardiovascular, hepatic and renal diseases were uncommon. On the other hand, infections were the leading causes of death in this population, notably opportunistic infections. Tuberculosis was the single most important opportunistic infection causing death.

Disseminated TB was the commonest form, with pulmonary $\mathrm{TB}$ running a close second and $\mathrm{TB}$ meningitis, third. Likewise in a study conducted in Burkina Faso on determinants and causes of mortality in HIV patients on HAART between 2003 and 2008, a multivariate analysis showed that clinical stage, BMI, CD4 count and treatment regimen were significantly associated with death. Common causes of mortality were wasting syndrome, tuberculosis and anemia. ${ }^{7}$

The pattern of diseases causing death in Ghana and Burkina Faso could be attributed to the low penetration of antiretroviral therapy amongst the population studied and also the fact that these countries still continue to have a high burden of communicable diseases as compared to non-communicable diseases. The pattern also depicts the severe immune suppression that exists in the in -patients.

In a study by Agaba et al ${ }^{15}$ on predictors of mortality in hospitalized HIV patients in Nigeria, tuberculosis was the common diagnosis accounting for $33.6 \%$ of the deaths. Pulmonary disease accounted for $53 \%$ and extra-pulmonary $47 \%$ of TB cases. In this study, tuberculosis was again the commonest cause of death accounting for $57.7 \%$ of all deaths. However in contrast to findings from Agaba, disseminated and extrapulmonary accounted for $75 \%$ of cases whilst pulmonary TB was $25 \%$.

In this study, we have shown that a significant proportion of TB deaths (10\%) were not diagnosed prior to death. This highlights the need for better diagnostic tools for TB a situation which to date has only marginally improved. In about threequarters of the cases studied, at least one premortem finding was confirmed by autopsy, attesting to the high clinical acumen of the physicians involved and the specificity of the post mortem diagnosis. This is in contrast to the study on causes of mortality conducted by Sackoff, where he observed that death certificates issued lacked specificity of the cause of death. ${ }^{12}$
With regard to demographic characteristics, patients dying from ADIs differed from those dying from non-ADIs only in morbidity. This finding was rather surprising as we expected the opposite, given our definition of morbidity as number of concurrent illnesses at the time of death. In a study on AIDS and non-AIDS mortality in the era of antiretroviral therapy by Falster et al ${ }^{16}$, they found that of 215 deaths, 89 were AIDS related, 97 non-AIDS related and 29 were unknown. They found age greater than 50 years and CD4 counts $>100$ increased the risk of non AIDS deaths (HR 4.99) whereas CD4 $\leq 100$ and viral load $>10,000$ increased the risk of AIDS deaths (HR 4.21). Most of our patients did not have CD4 counts and viral load tests were not available at the time.

Most of the patients in this study were not on HAART at the time of their death, suggesting a low admission rate of patients on HAART. Even though this rendered analyses by HAART use inconclusive, it shows the benefit of HAART in reducing morbidity severe enough to warrant admission and subsequently mortality. Increased use of HAART is likely to reduce mortality as shown in other studies around the world., $22-14$

Some of the admissions of patients on HAART were attributed to HAART related anaemia caused by zidovudine, one of the first line drugs. Availability and accessibility of blood and blood products continue to be a challenge for patient care. The relatively short duration of admission for most patients reflects the late presentation of HIV-infected patients at the health facility hence the high mortality rate.

Limitations of this study include the frequent inadequacy of death certificates and medical notes to identify causes of death; these are imperfect methods. The autopsy rate was just over $60 \%$ in this study. Another limitation was that immunological and virological parameters were not readily available for analysis due to late presentation, short duration of stay and financial challenges. Virological tests were not available at the time. Also, being a tertiary referral centre, mortality at the Fevers Unit may not be representative of HIV mortality in the community but rather in hospitals. Mortality in the community can only be ascertained using verbal autopsies.

\section{CONCLUSION}

The overall mortality rate for 2007 was 31.5\%. AIDSrelated causes accounted for $55.7 \%$ whereas HIVassociated causes accounted for $41.6 \%$ of total deaths. Together AIDS and HIV related deaths formed $97 \%$ of the deaths showing that the transition from HIV related deaths to causes of deaths similar to those of the general population had not yet occurred in the Unit. Autopsy findings confirmed at least one pre-mortem diagnosis in $76 \%$ of deaths. Tuberculosis was the single most important cause of death in the study population. 
Accuracy of TB diagnosis was average and still needed to be supported by better diagnostic tools. In a developing country like Ghana where HAART is yet to be widely accessible to PLHIVs, HIVrelated deaths remain the major cause of death.

\section{RECOMMENDATIONS}

We recommend further scale-up of the ART programme, early diagnosis of individuals and consistent supply of drugs and other consumables to reduce HIV related mortality, improve quality of life and increase life expectancy. Better diagnostic tools for TB are needed to assist clinicians and patients.

\section{ACKNOWLEDGEMENTS}

The authors wish to acknowledge all HIV-infected patients and the staff of Fevers Unit particularly Perfect Dzandu for collating and cleaning the data.

\section{REFERENCES}

1. Etard J-F, Ndiaye I, Thierry-Mieg M, Guèye NFN, Guèye PM, Lanièce I, et al. Mortality and causes of death in adults receiving highly active antiretroviral therapy in Senegal: a 7year cohort study. AIDS Lond Engl. 2006 May 12;20(8):1181-9.

2. Crum NF, Riffenburgh RH, Wegner S, Agan BK, Tasker SA, Spooner KM, et al. Comparisons of causes of death and mortality rates among HIV-infected persons: analysis of the pre-, early, and late HAART (highly active antiretroviral therapy) eras. J Acquir Immune Defic Syndr 1999. 2006 Feb 1;41(2):194-200.

3. Sun Hee Lee, Seung Geun Lee, Dong Hwan Chen, Dong Sik Jung, Chi Sook Moon, Ji Young Park, Joo Seop Chung, Ihm Soo Kwak, and Goon Jae Cho, Kye-Hyung Kim,. Trends of Mortality and Cause of Death among HIVInfected Patients in Korea, 1990-2011. J Korean Med Sci 201328 67-73. 2013;28:67-73.

4. De Olalla P, Novoa A, Clos R, Orcau A, Rodriguez-Sanz M, Cayla J. Increase in the NonHIV-Related Deaths Among Aids Cases in the HAART Era. Curr HIV Res. 2008 Jan $1 ; 6(1): 77-81$.

5. Simmons R, Ciancio B, Kall M, Rice B, Delpech V. Ten-year mortality trends among persons diagnosed with HIV infection in England and Wales in the era of antiretroviral therapy: AIDS remains a silent killer: Mortality in the era of ART. HIV Med. 2013 Jun; 14: 596604

6. Weber R, Ruppik M, Rickenbach M, Spoerri A, Furrer H, Battegay M, et al. Decreasing mortality and changing patterns of causes of death in the Swiss HIV Cohort Study: Causes of death and HIV infection. HIV Med. 2013 Apr;14(4):195-207.

7. Kouanda S, Meda IB, Nikiema L, Tiendrebeogo S, Doulougou B, Kaboré I, et al. Determinants and causes of mortality in HIV-infected patients receiving antiretroviral therapy in Burkina Faso: a five-year retrospective cohort study. AIDS Care. 2011 Dec 7;1-13.

8. Yang C-H, Huang Y-F, Hsiao C-F, Yeh Y-L, Liou H$\mathrm{R}$, Hung C-C, et al. Trends of mortality and causes of death among HIV-infected patients in Taiwan, 19842005. HIV Med. 2008 Aug;9(7):535-43.

9. JC2484_treatment-2015_en.pdf [Internet]. [cited 2013 Aug 27]. Available from: http://www.unaids.org/en/media/unaids/contentassets/ documents/unaidspublication/2013/JC2484_treatment2015_en.pdf

10. Djomand G, Roels T, Ellerbrock T, Hanson D, Diomande F, Monga B, et al. Virologic and immunologic outcomes and programmatic challenges of an antiretroviral treatment pilot project in Abidjan, Côte d'Ivoire. AIDS Lond Engl. 2003 Jul;17 Suppl 3:S5-15.

11. Schneider E, Whitmore S, Glynn KM, Dominguez K, Mitsch A, McKenna MT, et al. Revised surveillance case definitions for HIV infection among adults, adolescents, and children aged $<18$ months and for HIV infection and AIDS among children aged 18 months to $<13$ years--United States, 2008. MMWR 2008 Dec 5;57(RR-10):1-12.

12. Sackoff JE, Hanna DB, Pfeiffer MR, Torian LV. Causes of death among persons with AIDS in the era of highly active antiretroviral therapy: New York City. Ann Intern Med. 2006 Sep 19;145(6):397-406.

13. Bonnet F, Morlat P, Chêne G, Mercié P, Neau D, Chossat I, et al. Causes of death among HIV-infected patients in the era of highly active antiretroviral therapy, Bordeaux, France, 1998-1999. HIV Med. 2002;3(3):195-9.

14. Palella FJ Jr, Baker RK, Moorman AC, Chmiel JS, Wood KC, Brooks JT, et al. Mortality in the highly active antiretroviral therapy era: changing causes of death and disease in the HIV outpatient study. $J$ Acquir Immune Defic Syndr 1999. 2006 Sep;43(1):2734.

15. Agaba AP, Digin E, Makai R, Apena L, Agbaji O, Idoko J, Murphy R, Kanki P. Clinical characteristics and predictors of mortality in hospitalised HIVinfected Nigerians. J Infect Dev Ctries 2011; 5(5):377382.

16. Falster K, Choi JY, Donovan B, Duncombe C, Mulhall B, Sowden D, Zhou J, Law MG. AIDS and non-AIDS related mortality in the Asia Pacific region in the era of combination antiretroviral treatment. AIDS. 2009 November 13; 23(17): 2323-2336 